\title{
Assessment of Homemade Liquor “Tharra” Quality by GC-FID and its Potential Impacts on Human Health
}

\author{
UZMA IMRAN*, AWAIS ANWAR CHANDIO*, JAMIL AHMED SOOMRO*, HARESH KUMAR**, \\ AND RAFI-U-ZAMAN BROHI** \\ RECEIVED ON 09.02.107 ACCEPTED ON 29.05.2017
}

\begin{abstract}
The unsafe use of alcohol causes many diseases that lead to social and economic burden in societies. In Pakistan due to limited access, inflated prices of standard alcohol and ban on use of alcoholic products for Muslims, the illegal Liquors "Tharra” production at domestic level is on the rise. The liquor (Tharra) contain many impurities and is often injurious to health. This study examines the impact of consumption of unsafe liquor on socio-economic and health context in Pakistan by using primary data obtained through filling of suitably designed questionnaires and finding out quality of homemade liquor samples collected from local Bathas. The data was collected by taking representative samples consisting of males from age groups 14 to onwards. The participants were enrolled using CAGE (screening tool. Our data revealed that majority of middle age group (57\%) was involved in liquor "Tharra" drinking (36- 45 years and 26 - 35 years). More participants (63\%) were found representing Hindu religion, followed by Muslims (31\%) with few Christian (5\%) in the studied area. Almost in all samples the alcoholic strength exceeded by safe volume limit (20\%). All other analyzed constituents of the samples (e.g.methanol, acetaldehyde, higher alcohols, esters, metals, anions) were found in concentrations that poses serious threat to public health. It seems impossible for the government to subsidize its prices or lift ban on the use and purchase of standard alcohol products due to social and religious reasons. However, the government needs to reinforce the laws governing sale of methylated spirits for industrial and commercial use.
\end{abstract}

Key Words: Alcohol, Illegal Liquor, CAGE Screening Tool, Liver Profile.

\section{INTRODUCTION}

“Tharra” is an illegally made local alcohol with a very low quality and is fermented from any fruit that has a high sugar content, including sugarcane, orange, banana, pineapple, and palm; carrying many impurities and is often injurious to health. In the scientific literature, different definitions of the term 'alcohol quality' have been reported, which may lead to misunderstanding; and hence it is important to define the term appropriately whenever used [1]. We therefore define the term 'alcohol quality' as the 'lower quality' of homemade unrecorded alcohol, to

Corresponding Author (E-Mail: jamilahmed.uspcasw@faculty.muet.edu.pk)

* US-Pakistan Center for Advanceed Studies in Water, Mehran University of Engineering \& Technology, Jamshoro,

** Instituteof Environmental Engineering \& Management, Mehran University of Engineering \& Technology, Jamshoro.

Mehran University Research Journal of Engineering \& Technology, Volume 36, No. 4, October, 2017 [p-ISSN: 0254-7821, e-ISSN: 2413-7219] 
be called as "tharra" in this article, in terms of its impacts related with public health and socioeconomic status of drinkers and is interpreted as 'more toxic' as compared to the commercially available alcohol products of similar kind which are generally approved for its toxicity and taste quality characteristics through standard procedures. Hence further narrowing the above illustrated definition, we have limited the term alcohol quality to the measure of volatile compounds detected through GC (Gas Chromatography) with FID (Flame Ionization Detection) technique in as-collected samples of tharra without taking into its manufacturing process and/or the time differences of its manufacturing, storage, consumption and laboratory detection into account.

The WHO's global disease burden report shows that the alcohol is the leading cause of disability worldwide among which about 140 million people in the world are dependent on alcohol [2]. The unsafe use of alcohol causes many diseases that lead to social and economic burden in societies. In addition to the acute health problems that include acute liver damage, gastric problems, toxicity effect on nervous system; the alcohol consumption may cause coma with immediate death and unintentional injuries such as burns, falls, firearm injuries, drowning, child neglect cases, unprotected sex transferring sexually transmitted diseases (HIV/AIDS, Hepatitis B-C, Syphilis). While, those who drink large amounts of alcohol over a number of years may develop chronic diseases e.g. liver cirrhosis, cancer, neurological impairment, cardiovascular diseases (Hypertension, Myocardial infarction).

The GC-FID has been used for the investigation of influence of mycotoxins on the presence of aldehydes and higher alcohols in corn distillates, identification of volatile compounds responsible for the spirit's aroma in Thai spirit made of sticky rice [3], determination of volatile compounds (methanol, acetaldehyde, higher alcohols) in homemade (unrecorded) spirits of Lithuania and Hungary [1] and in other studies for the determination of volatile compounds in vodka [4], rum [5], cachaça (a distilled spirit made from sugarcane juice) [6-7], spirits, whiskey and Chinese medicinal liqueur [8-9]; and for the determination of aromatic compounds in Tequila [10], volatile compounds in spirits made from oranges [11], pear distillates [12], Mulberry spirit [13], fruit based spirits (brandy) [14] as well as for the determination of ethanol content in brandy [15], cider [16-17] and homemade liquors in Vietnam [18].

Various studies have been conducted to find the causes responsible for people to use the dangerous locally made liquor. A study by WHO (World Health Organization) found that alcohol contributes to 5.9\% of all global deaths annually and overall 200 diseases and health conditions. In various parts of the world, alcohol drinking is a common feature of social gatherings [2].A study on alcohol consumption in Uganda found that unemployment and poor economic conditions were responsible for use of alcohol [19] it was also reported in the article that more and more young people are starting to use alcohol at lower age. The study also found very low trend of smoking and alcohol consumption in females due to age, culture and regional social customs [19].

Another study conducted in Pakistan reported the female involvement in cigarette smoking as $5 \%$ while the remaining 95\% were reported with no smoking habit at all. Similarly, only $2.5 \%$ female population used alcohol while $97.5 \%$ never used alcohol at all. On contrary, the caffeine intake in the region was reported prevalent in female population as compared to cigarette smoking and alcohol consumption. The study reported that $95 \%$ pre term females took caffeine and a small share of $5 \%$ did not [20]. 
An Indian study reported that the cultural differences strongly influenced the pattern of alcohol use, and further pointed out that alcohol consumption was associated with the group of diseases whose impact on overall global burden of diseases is anticipated to increase [21].

Similarly, in a multinational study in Europe, the results showed that almost $36 \%$ of unrecorded alcohol products were homemade brew containing toxic level of flavoring, methanol and contained $60 \%$ alcohol by volume [22].

Several studies have been conducted on the determination of alcohol quality and its volatile composition in the scientific literature till today. Lechenmeire et. al. [18] determined alcoholic strength, volatiles (methanol, acetaldehyde, higher alcohols), ethyl carbamate, anions (including nitrate) and inorganic elements (including lead) from alcohol products sold in markets of Lithuania and Hungary and found the higher alcohol concentrations of $60 \%$ by volume in unrecorded alcohol products [1]. Similarly, in another study in Vietnam, a homemade sample of alcohol with pickled snakes and scorpions contained 77\% volume of alcohol, $76.7 \%$ vol. of ethanol, $75 \mathrm{~g} / \mathrm{hL}$ pure alcohol of methanol, $13 \mathrm{~g} / \mathrm{hL}$ pure alcohol of acetaldehyde, $12 \mathrm{~g} / \mathrm{hL}$ pure alcohol of ethyl acetate [23].

The reported alcohol consumption in Pakistan is very low (2-5\% of the population), which is presumed as 'under reported' because of strong religious obligations and strict country law over alcohol consumption for Muslims (i.e. 96\% of country's population is Muslim) [2]. The law forbids Muslims to purchase, transport, and possess beverages containing alcohol. However non-Muslims are entitled with special permit to buy liquor from three main registered brewers that prepare various types of wines within the country. Due to above mentioned restrictions on access, purchase, transport etc. the (unreported) homemade brew production is on the rise in the country [24].
The homemade liquor "Tharra” contains methanol mix liquor which is quite toxic and the licensed alcohol contains more quantity of ethanol which is safe as compared to methanol. In Sindh province of Pakistan, the fatalities due to consumption of homemade liquor are mostly reported by media from time to time mainly from districts Umerkot and Mirpurkhas. However, there is no research work done on this much neglected topic. Therefore, this work will contribute towards the analysis of the quality of tharra and its impact on the human health and socioeconomic life of the consumers in selected districts of Sindh province, Pakistan.

The purpose of this study is to investigate the impacts of tharra on consumer's health and socioeconomic life in Mirpurkhas and Umerkot districts of Sindh province of Pakistan.

\section{MATERIALS AND METHOD}

\subsection{Sampling and Analysis of Liquor}

For the determination of homemade liquor "tharra" quality of the volatile compounds, i.e. methanol, ethanol, propanol, butanol and isobutanol, twenty samples of tharra were collected from both the districts of Mirpurkhas $(n=10)$ and Umerkot $(n=10)$. The samples were received in the plastic bags, which were then poured into the $500 \mathrm{~mL}$ plastic bottles which were washed with distilled water and dried at room temperature. The sample bottles were transported to the laboratory of Institute of Environmental Engineering and Management, Mehran University of Engineering \& Technology,Jamhsoro, Pakistan within 3 hours where the samples were immediately refrigerated at $4^{\circ} \mathrm{C}$. The volatile components of the samples were then analyzed on the basis of the European Community Reference Methods for the Analysis of Spirits using GC with a FID technique [25]. The GC-FID model used for the analysis was GC-2010 Plus, Schimadzu Japan. The concentrations of $10,15,20$, and $25 \%$ of each standard

Mehran University Research Journal of Engineering \& Technology, Volume 36, No. 4, October, 2017 [p-ISSN: 0254-7821, e-ISSN: 2413-7219] 
compound (volume up to $2 \mathrm{~mL}$ ) were prepared in acetonitrile solvent (99-100\% by volume) [4]. The mixture was shaked and $2 \mu \mathrm{L}$ volume was injected to GC. Similarly, all the samples of tharra were analyzed directly on GC by setting the initial column oven temperature at $50^{\circ} \mathrm{C}$ held for $1 \mathrm{~min}$. with ramp temperature of $10-15^{\circ} \mathrm{C}$ held for $3 \mathrm{~min}$, the detector temperature was set at $220^{\circ} \mathrm{C}$. The nitrogen was used as mobile phase with flow rate of $0.50 \mathrm{~mL} / \mathrm{min}$. and the split ratio of 300:1. In FID detector, the hydrogen gas flow rate of $40 \mathrm{~mL} / \mathrm{min}$ and air flow rate of $400 \mathrm{~mL} / \mathrm{min}$ were set.

\subsection{Socioeconomic and Health Impacts Survey}

This research was conducted by obtaining primary data for analysis.For this purpose, a cross-sectional survey was conducted in Mirpurkhas and Umerkot districts from January to October 2016. A representative sample consisting of one hundred and thirty (130) persons were collected randomly from 10 identified places "Batha" where tharrais being prepared and sold. Two teams were constituted for data collection (2 persons in each team) who had relevant understanding and knowledge of the areas under survey for data collection. The teams were also given brief training for filling of survey questionnaires.

The participants were enrolled using Cutting down, Annoyance by criticism, Guilty feeling, and Eye-openers (CAGE) screening tool [26]. The tool was designed to identify those indicating alcohol problem. Those participants who were found to be qualified on CAGE tool were considered as 'relevant population', and were studied further, but those who didn't qualify on CAGE score were excluded from our study.

In the second part, we interviewed people visiting bathas (wine shops) for buying tharra. A structured questionnaire was designed to collect the data. The questionnaire consisted of two types of questions regarding health and socioeconomic conditions of tharra consumers.

The questions regarding health included information regarding consumers' illness, mental status and history of consultation with healthcare provider, which is similar to previous studies Rehm et. al [27-28]. The questions about socioeconomic conditions included characteristics of liquor consumers such as history and frequency of tharra consumption, self-control, effect on family life, level of education, family income, age, religion and faith of the respondents.

The parameters studied included age, family income, religion, level of education, age at first drink, frequency of drinking, amount and duration of drinking, health effects on drinking, desire for quitting and biomarkers. SPSS (Statistical Package for Social Sciences) version 22.0 was used for social data analyses.

\subsection{Blood Sampling from Liquor Consumers}

The blood samples of the participants were collected to assess their liver profile. The blood was assessed at pathology laboratory of the Civil Hospitals of the respective sampling districts. Two tests from each blood sample were conducted, the GGT (Gamma GlutamylTransferase) test to know the status of recent alcohol consumption and SGPT (Serum Glutamic-Pyruvic Transaminase) to see the status of liver damage. The data was analyzed on SPSS.The descriptive statistics was used to assess the percentages and levels of significance. The $\mathrm{P}$ values less than 0.05 were considered significant.

\section{RESULTS}

\subsection{Analysis of Liquor Samples}

The Linearity of calibration curves of eight organic volatile compounds were evaluated by recording average peak area/peak height against concentration and was observed

Mehran University Research Journal of Engineering \& Technology, Volume 36, No. 4, October, 2017 [p-ISSN: 0254-7821, e-ISSN: 2413-7219] 
in the range of $10-25 \%$ with split ratio of 300:1 with coefficient of determination $\left(\mathrm{R}^{2}\right)$ within 0.932 - 0.992. The linear regression equations for each volatile organic compound, based on calibration are given in Table 1.

\subsection{Chromatogram of Mixed Compounds}

The chromatogram of all the mixed eight compounds as examined on GC is given in the figure below. The GC-FID column TRB-5 at different programmed temperatures and hydrogen flow rates was selected. The column flow rate was set at $0.50 \mathrm{~mL} / \mathrm{min}$. Complete separation was achieved between two nearby peaks. The total run time was 8.0 min. The split ratio was 300:1. The chromatogram of eight mixed organic volatile compounds is shown in Fig 1.

The volatile compounds (in percent) in tharra samples obtained from both the districts are given in Tables 2-3.

Methanol was detected in concentrations ranging from undetectable to $59.5 \pm 3.9 \%$ in S8 of Tharra obtained from Mirpurkhas district, while the methanol concentrations

TABLE 1. CALIBRATION CURVES OF MIXED COMPOUNDS

\begin{tabular}{|c|c|c|c|c|}
\hline Compounds & $\begin{array}{c}\text { Retention Time } \\
\text { (minutes) }\end{array}$ & $\begin{array}{c}\text { Calibration Range } \\
(\%) \\
\end{array}$ & $\begin{array}{l}\text { Coefficient of Determination } \\
\left(\mathrm{R}^{2}\right)\end{array}$ & $\begin{array}{c}\text { Linear Regression } \\
\text { Equation } \\
\end{array}$ \\
\hline Ethanol & 4.1 & $10,15,20,25$ & $\mathrm{R}^{2}=0.9678$ & $y=46552 x+157780$ \\
\hline Methanol & 4.0 & $10,15,20,25$ & $\mathrm{R}^{2}=0.9414$ & $y=4788 x+65142$ \\
\hline Butanol & 4.7 & $10,15,20,25$ & $\mathrm{R}^{2}=0.9796$ & $y=7234 x+5321$ \\
\hline Isobutanol & 4.5 & $10,15,20,25$ & $\mathrm{R}^{2}=0.935$ & $y=96648 x+11644$ \\
\hline Propanol & 4.3 & $10,15,20,25$ & $\mathrm{R}^{2}=0.992$ & $y=60311 x+70752$ \\
\hline 2-Propanol & 4.2 & $10,15,20,25$ & $\mathrm{R}^{2}=0.967$ & $y=46552 x+15778$ \\
\hline Formaldehyde & 5.0 & $10,15,20,25$ & $\mathrm{R} 2=0.961$ & $y=16223 x-20341$ \\
\hline
\end{tabular}

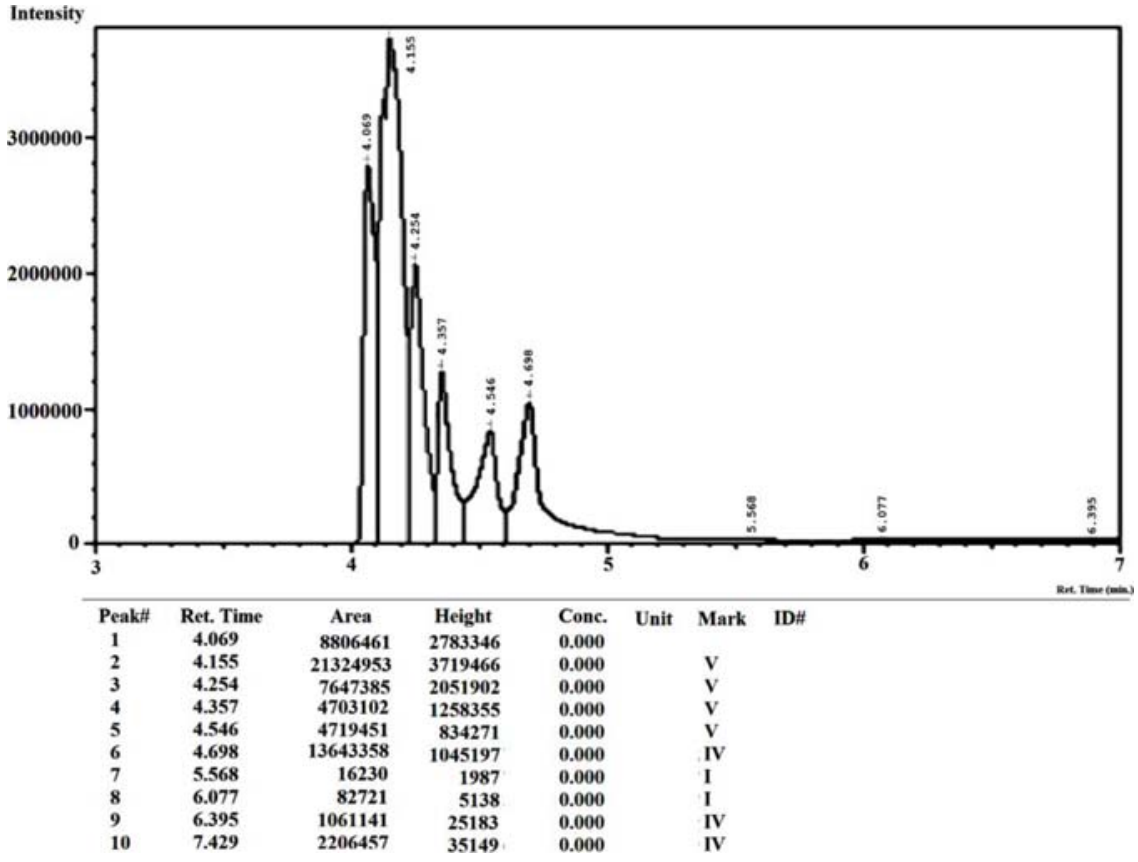

FIG. 1. CHROMATOGRAM OF EIGHT MIXED VOLATILE COMPOUNDS 
ranging from $36.74 \pm 1.55 \%$ in S3 to $89.28 \pm 3.4 \%$ in S10 was detected from Tharra samples obtained from Umerkot district. The detected concentrations of ethanol ranged from 17.14-46.90 in five Tharra samples S1-S5 and undetected in the remaining samples; concentration of propanol was detected as 0.71 in only one of the sample, that is, in S6; concentrations of ISObutanol was detected in ranges from 0.87-3.28 in five samples S2-S6 and undetected in the remaining samples obtained from Mirpurkhas district. It was interesting to note that there were no other volatile compounds detected other than methanol in the Tharra samples obtained from Umerkot district.

\subsection{Socioeconomic and Health Conditions}

The health and socioeconomic characteristics of tharraconsumers were studied to assess the potential health impacts and socioeconomic situation of tharraaddicts. The data reflects that the majority of middle age group (57\%) was involved in tharra drinking (36-45 years and 26-35 years). More participants (63\%) were found representing Hindu religion, followed by Muslims (31.5\%) with few Christian (5.4\%).The respondents were mostly illiterate (46.2\%) or had education up to primary level (28.5\%).

TABLE 2. VOLATILE COMPOUNDS IN THARRA SAMPLES OBTAINED FROM DISTRICT MIRPURKHAS DISTRICT

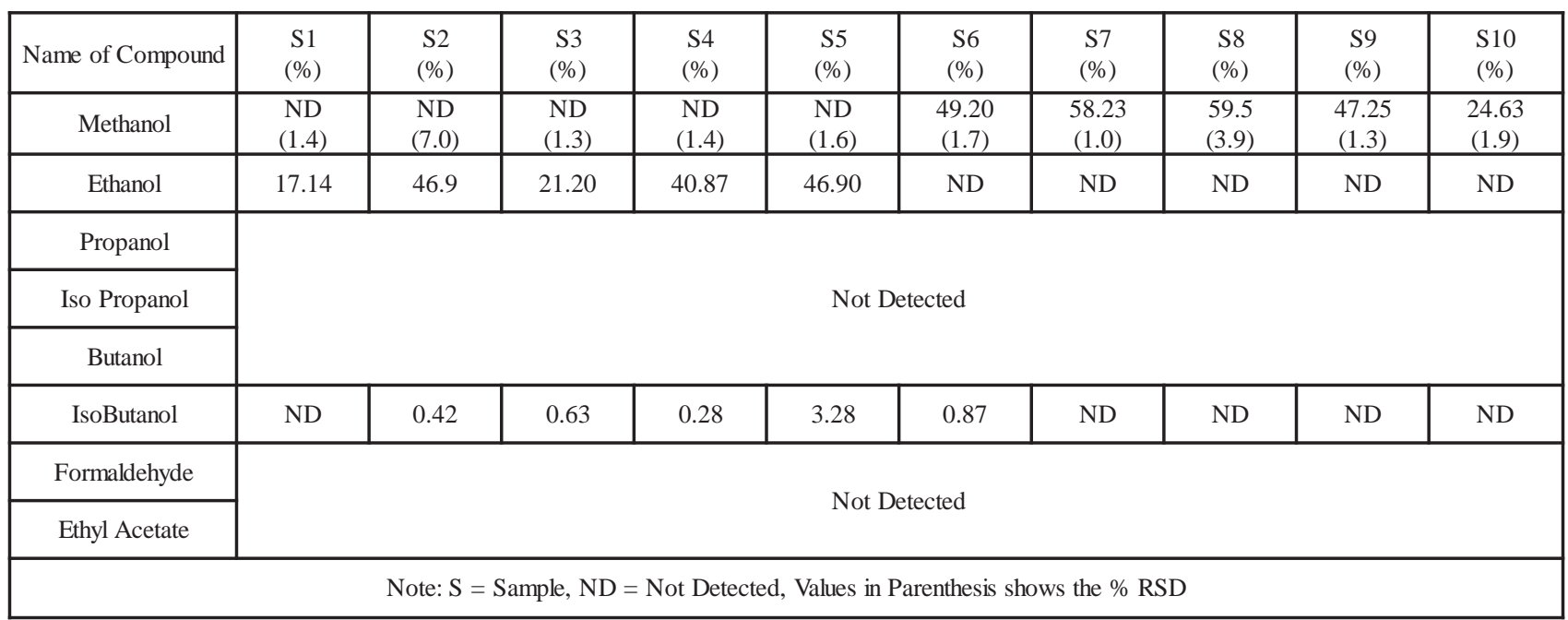

TABLE 3. VOLATILE COMPOUNDS OF THARRA SAMPLES OBTAINED FROM DISTRICT UMERKOT DISTRICT

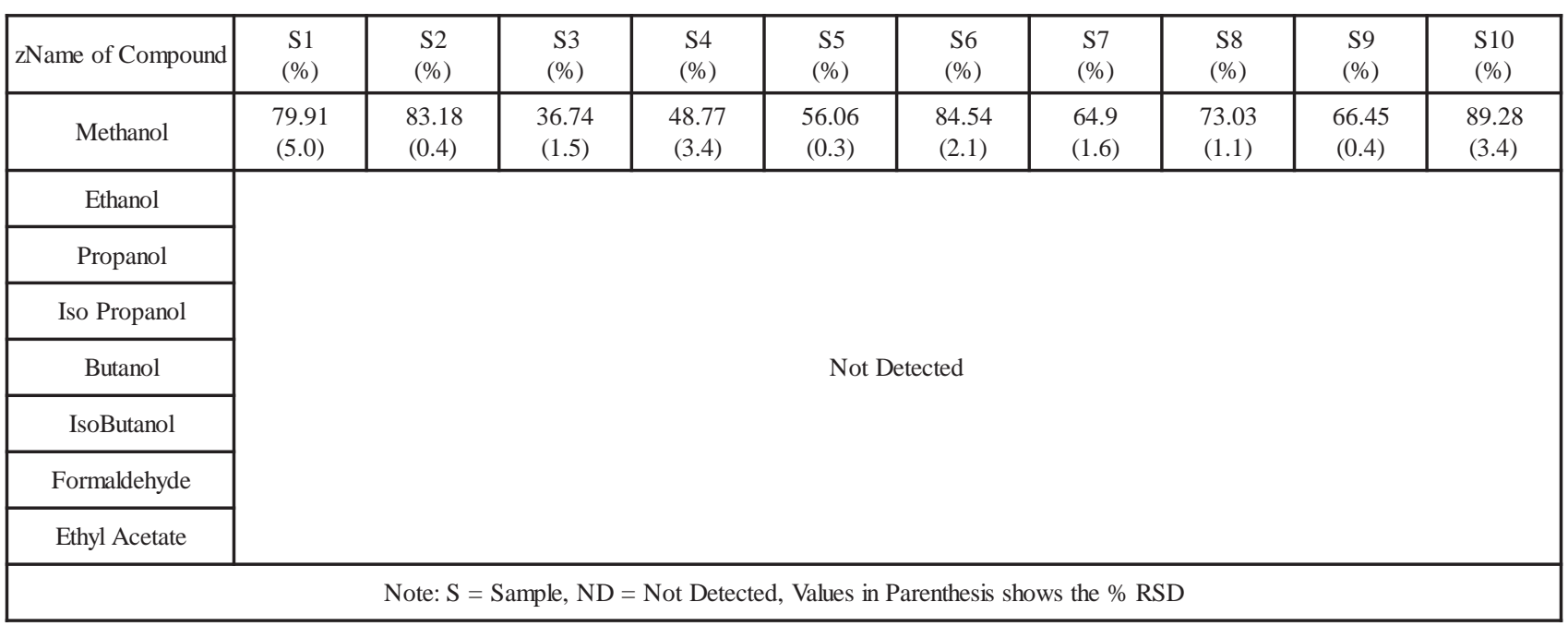

Mehran University Research Journal of Engineering \& Technology, Volume 36, No. 4, October, 2017 [p-ISSN: 0254-7821, e-ISSN: 2413-7219] 
Overall the economic status of tharra drinkers was poor (91\% monthly family income below $<$ PKR 30,000). Most of the tharra consumers' age at their first intake was reported above 19 years (40\%), however ample number of participants (14\%) started drinking at early ages (i.e. below 19 years). We further explored that one glass intake (i.e. $58 \%$ ) of tharra was common among consumers, although around 28\% preferred consuming two glasses on tharra each time when they drink. The history of recent intake of tharra was more pronounced (i.e. tharra consumed 'last night' $38 \%$ ) as compared to occasional drinking or on some social events such as marriages, pilgrimages, fairs, and/or families and friends 'gatherings.

Majority of the participants (i.e. 67\%) were of the view that they drink as part of their habit(s) to satisfy their addiction, however a noticeable number of participants (i.e. 33\%) also reported to drink to get relief from the distress or sorrows. Surprisingly, the majority of tharra addicts showed desire to quit drinking it, however they found it very challenging.

Almost half of the subjects reported to live in isolation or had distanced themselves from their social network. The tharra intake was mainly influenced by peer pressure (i.e. $69 \%)$. The participants also documented frequent family quarrels due to their drinking habits, as shown in Table 4.

The results from the aspect of socio-economic conditions for drinking locally made unsafe liquor showed a clear trend. Almost $90 \%$ of people surveyed tend to drink due to social or peer pressure. They used to drink when they wanted or wished. But, survey showed that $92 \%$ of the people did not go to doctor for check-up without realizing the harmful impacts of consuming unsafe liquor "tharra" on their health. This showed that low education, backwardness and lack of awareness were main socioeconomic causes of the use of tharra. Also, the majority of people (60\%) did not enjoy drinking and drank for minimizing the sufferings and hardships and to escape pains which life offered to them. We found statistically significant difference $(P=0.05)$ in frequency of tharra drinking by type of religion.
The pattern of tharra consumption showed that Muslim respondents usually drink on daily basis, contrary to this, most of the Hindus drink alternatively, while some also drink regularly or after three days or even fair number of respondents do so on weekly basis (Fig. 2).

Almost 35\% respondents complained of deterioration in health after drinking as shown in Fig. 3.

In Table 5, we tried to compare respondents' desire for giving up drinking by age. The results explored that more people (i.e. 73.8\%) wanted to give up drinking. Among those who wanted to give up drinking tharra, the majority of people having age above 36 wanted to quit drinking as compared to the rest of the other drinkers. Almost all participants with age group 36-45 years wished to give up drinking tharra as compared to very few within the age group 14-25 years showing similar desire.

\subsection{Potential Health Impacts}

Another result obtained in this study pertains to evaluation of impact on health due to consumption of unsafe liquor as shown in Table 6.

The mean age of tharraconsumers were $32 \pm 5$. The mean duration of drinking tharra was 12.7 years.

In order to assess the status of liver function and frequency of tharra intake, we did standard laboratory investigation of each participant for SGPT and GGT tests. The results confirmed that the majority (80\%) of the participants' SGPT and GGT were elevated than the required standard normal ranges, which means biomarkers (SGPT and GGT) confirmed that most of the subjects were found as chronic drinkers of tharra; and as a result of toxic nature of tharra, their livers were inflamed or injured (as in Hepatitis). Majority of participants had SGPT ranging between 71-130 IU/L and above $200 \mathrm{IU} / \mathrm{L}$, while GGT ranging above $200 \mathrm{IU} / \mathrm{L}$ in $42.3 \%$ of the participants. The GGT test also gave the clue of history of heavy drinking of tharra as shown in Table 6. 
Assessment of Homemade Liquor "Tharra" Quality by GC-FID and its Potential Impacts on Human Health

TABLE 4. HEALTH AND SOCIOECONOMIC CHARACTERISTICS OF LIQUOR”THARRA” CONSUMERS

\begin{tabular}{|c|c|c|c|c|c|}
\hline Characteristics of Consumers & $\begin{array}{c}(\mathrm{n}=130) \\
\text { Frequency }\end{array}$ & Percent & Characteristics of Consumers & $\begin{array}{l}(\mathrm{n}=130) \\
\text { Frequency }\end{array}$ & Percent \\
\hline At what age did you started drinking? & & & How much do you drink? & & \\
\hline $14-19$ & 24 & 18.5 & 1 Glass & 76 & 58.5 \\
\hline$>19-30$ & 52 & 40.0 & 2 Glassless & 36 & 27.7 \\
\hline$>30-45$ & 42 & 32.3 & $>2$ Glassless & 18 & 13.8 \\
\hline$>45$ & 12 & 9.2 & $\begin{array}{l}\text { Do you started drinking due to peer } \\
\text { pressure? }\end{array}$ & & \\
\hline When did you last drink? & & & Yes & 90 & 69.2 \\
\hline Last night & 49 & 37.7 & No & 30 & 23.1 \\
\hline Two days ago & 35 & 26.9 & $\begin{array}{l}\text { Do you have control when to stop } \\
\text { drinking? }\end{array}$ & & \\
\hline Three days ago & 21 & 16.2 & Yes & 30 & 23.1 \\
\hline 4-7 Days ago & 19 & 14.6 & No & 100 & 76.9 \\
\hline >7 Days ago & 6 & 4.6 & Have you ever fallen ill after drinking? & & \\
\hline How frequently do you drink? & & & Yes & 46 & 35.4 \\
\hline Daily & 45 & 34.6 & No & 84 & 64.6 \\
\hline Alternate day & 36 & 27.7 & $\begin{array}{l}\text { Do you consult doctor for drinking } \\
\text { related issue? }\end{array}$ & & \\
\hline Three days later & 20 & 15.4 & Yes & 26 & 20.0 \\
\hline Weekly & 29 & 2.3 & No & 104 & 80.0 \\
\hline $\begin{array}{l}\text { Do you drink to get relief from distress } \\
\text { and unhappiness? }\end{array}$ & & & Total & 130 & 100.0 \\
\hline YES & 43 & 33.1 & $\begin{array}{l}\text { Do you have quarrels with family after } \\
\text { drinking? }\end{array}$ & & \\
\hline NO & 87 & 66.9 & Yes & 97 & 74.6 \\
\hline $\begin{array}{l}\text { Do you drink to get relief from distress } \\
\text { and unhappiness? }\end{array}$ & & & No & 33 & 25.4 \\
\hline Yes & 43 & 33.1 & Do you want to give up drinking? & & \\
\hline No & 87 & 66.9 & Yes & 96 & 73.8 \\
\hline Do you live without social interaction? & & & No & 34 & 26.2 \\
\hline Yes & 67 & 51.5 & Level of education & & \\
\hline No & 63 & 48.5 & No education & 60 & 46.2 \\
\hline Religion & & & Primary & 37 & 28.5 \\
\hline Muslim & 41 & 31.5 & Matriculation & 19 & 14.6 \\
\hline Hindu & 82 & 63.1 & Intermediate & 9 & 6.9 \\
\hline Christian & 7 & 5.4 & Bachelor & 3 & 2.3 \\
\hline Age & & & Master and above & 2 & 1.5 \\
\hline 14-25 years & 27 & 20.8 & Family income & & \\
\hline 26-35 Years & 34 & 26.2 & $<10,000$ & 43 & 33 \\
\hline 36-45 Years & 40 & 30.8 & $10,000-30,000$ & 76 & 58.4 \\
\hline 46- 60 Years & 18 & 13.8 & $31,000-80,000$ & 9 & 6.9 \\
\hline >61 Years & 11 & 8.5 & $>80,000$ & 2 & 1.52 \\
\hline
\end{tabular}

Mehran University Research Journal of Engineering \& Technology, Volume 36, No. 4, October, 2017 [p-ISSN: 0254-7821, e-ISSN: 2413-7219] 


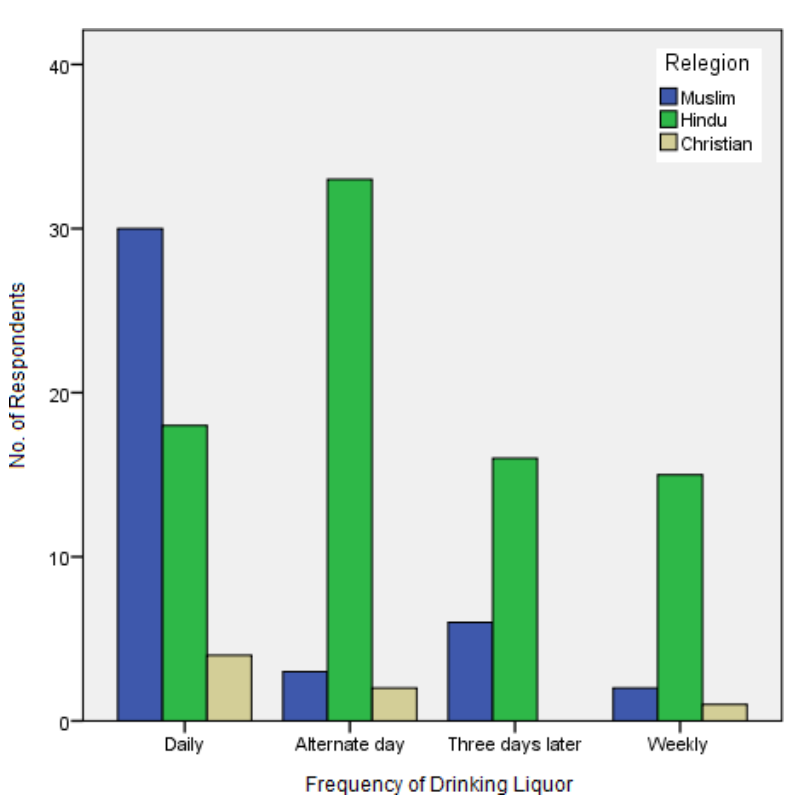

FIG. 2. COMPARISON OF FREQUENCY OF LIQUOR "THARRA” INTAKE BY RELIGION

\section{DISCUSSION}

\subsection{Quantitative Determination of Homemade Liquor(Tharra)}

From the earlier researches, major toxic effects of ethanol have been reported as acute intoxication and poisoning also causing more than 50 disease conditions including esophageal cancer $[26,29]$. No safe levels have been reported in any studies while 'low risk' drinking guidelines have been reported [22]. On the other hand, fatal poisoning and blindness was reported by Kruse due to methanol toxicity [30]. The maximum tolerable concentration of $2 \%$ methanol by volume was reported Paine et.al. [31]. They also reported that 5\% methanol: 95\% ethanol can cause severe and even fatal illness. Hence, it can be generalized that all the detected samples can cause severe and even fatal illness except the samples

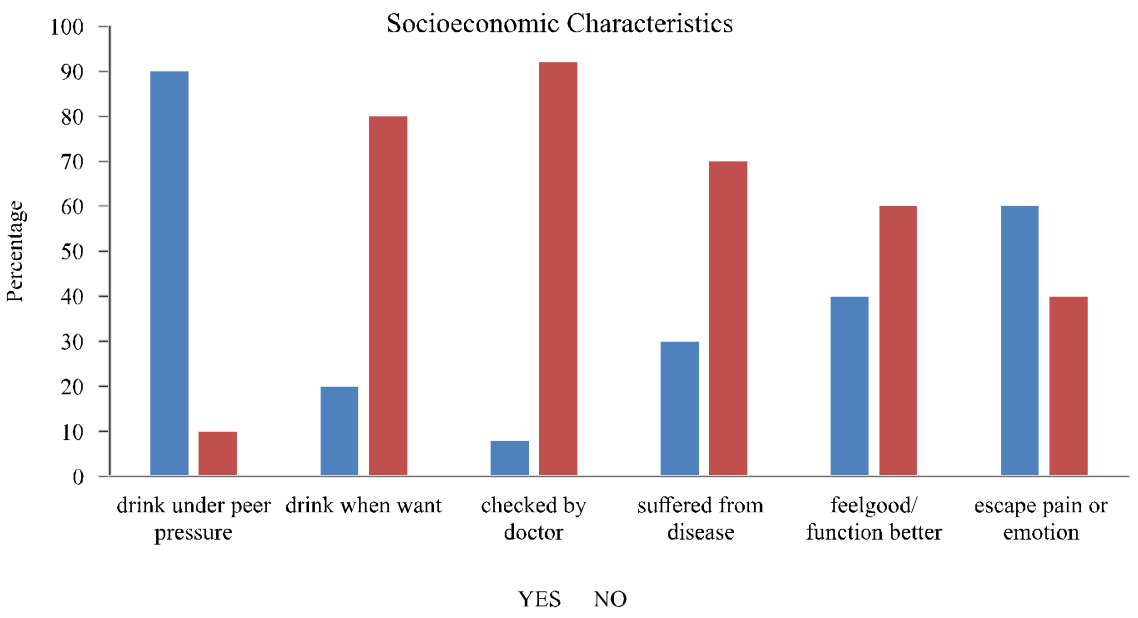

FIG. 3. ANALYSIS OF SOCIO-ECONOMIC QUESTIONNAIRE SURVEY

TABLE 5. COMPARISON OF DESIRE FOR GIVING UP DRINKING BY AGE

\begin{tabular}{|c|c|c|c|c|c|c|}
\hline \multirow{2}{*}{ Do you want to give up drinking } & \multicolumn{9}{|c|}{ Age } \\
\cline { 2 - 7 } & $14-25$ Years & $26-35$ Years & $36-45$ Years & $46-60$ Years & $>61$ Years & Total \\
\hline No. of Respondents & 12 & 24 & 40 & 16 & 46 \\
\hline Yes (\%) & $9.2 \%$ & $18.5 \%$ & $30.8 \%$ & $12.3 \%$ & $3.1 \%$ & 7 \\
\hline No. of Respondents & 6 & 10 & 0 & 11 & 34 \\
\hline No (\%) & $4.6 \%$ & $7.7 \%$ & $0.0 \%$ & $8.5 \%$ & $5.4 \%$ & 11 \\
\hline Total (No. of Respondents) & 18 & 34 & 40 & 27 & 130 \\
\hline Total & $13.8 \%$ & $26.2 \%$ & $30.8 \%$ & $20.8 \%$ & $8.5 \%$ & $100.0 \%$ \\
\hline
\end{tabular}

Mehran University Research Journal of Engineering \& Technology, Volume 36, No. 4, October, 2017 [p-ISSN: 0254-7821, e-ISSN: 2413-7219] 
S1-S5 obtained from Mirpurkhas district. We therefore conclude that further detailed evaluations must be made on reporting the manufacturing processes of all types of homemade alcohols "tharra" from both the studied areas in future and the risk assessment studies should be conducted through cohort studies on human population consuming tharra.

\subsection{Socioeconomic and Health Determinants of Liquor Consumers}

In our study the mean age of the tharraconsumers was around $32 \pm 5$, similar to studies by Butt and Chaudhary $[24,32]$ who reported range between $30 \pm 40$ and $31 \pm 5$ years respectively in contrast to our findings. A study in Pakistan reported the mean age ranges between $25 \pm 5$ years. The difference could be because the later study focused only hospital indoor patients diagnosed with alcohol toxicity whereas we considered enrolling participants' appropriateness from the place of purchase or distribution [32].

Our study further explored that, most of the liquor consumers, drink tharra on daily basis $(37.7 \%)$ as compared to a similar kind of study in other province of Pakistan named Punjab and in Nepal [32-33] showed similar trends of $40 \%$ and $38 \%$ respectively, however our findings vary from the studies conducted in India and Tanzania where the homemade liquor consumption was reported as 48and 14.7-47 \% respectively [33-34].
Almost $69 \%$ of tharra consumers in our study had started drinking due to peer pressure, which is more or less similar to studies in Tanzania, India and Bangladesh [33-34]. Peer pressure, indirect or direct inspiration from friends, family colleagues especially of same age group is considered very important influencing factors that may involve persons in risky activities/behaviors such as alcohol use, tobacco use and drug use. Moreover, peers contribute significantly in providing introducing or pressuring risky activities i.e. the use of homemade (unsafe) liquor to other peers [2]. In our study, we witnessed $69 \%$ of the respondents who started drinking due to peer pressure, almost similar to studies conducted in Tanzania and Bangladesh [33-34].

\subsection{Blood SamplingAnalysis}

Our study biomarkers (SGPT and GGT) revealed that most of the subjects (almost 80\%) were found chronic tharradrinkers and further the elevated SGPT in results also suspected the cases of inflamed liver (Hepatitis). A similar study was conducted in India, who reported around $70 \%$ cases with similar biomarkers findings and is inconsistent with the studies [23,33]. The difference could be due to difference in study setting and methodology. One local study has been done at single study setting and had used BAC (Blood Alcohol Concentration) to assess illegal alcohol (tharra) concentration [32]. The BAC is very good biomarker for measurement of blood ethanol concentration present in regular alcohol brands rather

TABLE6. BLOOD SAMPLES OF HOMEMADE LIQUOR(THARRA) CONSUMERS FOR SERUM GLUTAMIC-PYRUVIC TRANSMINASEAND GAMMA GLUTAMYLTRANSFERASE

\begin{tabular}{|c|c|c|c|c|c|}
\hline $\begin{array}{c}\text { SGPT Result } \\
\text { Normal Range: 0-40IU/L }\end{array}$ & Frequency & Percent & $\begin{array}{c}\text { GGT Result } \\
\text { (Normal Range: 0- 50IU/L) }\end{array}$ & Frequency & Percent \\
\hline $0-30$ & 13 & 10.0 & $0-40$ & 12 & 15 \\
\hline $31-40$ & 12 & 9.2 & $41-50$ & 14 & 7.2 \\
\hline $41-70$ & 27 & 20.8 & $51-80$ & 71.5 & 5.4 \\
\hline $71-130$ & 37 & 28.5 & $131-200$ & 27 & 20.8 \\
\hline $131-200$ & 14 & 10.8 & $>200$ & 55 & 42.3 \\
\hline$>200$ & 27 & 20.8 & Total & 130 & 100 \\
\hline
\end{tabular}

Mehran University Research Journal of Engineering \& Technology, Volume 36, No. 4, October, 2017 [p-ISSN: 0254-7821, e-ISSN: 2413-7219] 
than to measure methyl and other chemicals present in homemade liquors, such tharra. We used SGPT and GGT to measure how much alcohol has been drunk, may estimate duration and the speed of drinking.

We found few limitations in our study. Firstly, generalization of our results on tharrafor rest of the country may need to be considered carefully as there may be difference in social and cultural trends which therefore may limit estimation of results in other parts. Secondly, due to inadequate information we didn't consider alcohol prepared at home by group of people on special events such as, eid days, holi, deewali, marriage ceremonies etc., which mainly brought several causalities from time to time as reported through media sources. Finally, within our limited resources, we were able to collect data from two districts of Sindh, hence a detailed and multi settings study is highly recommended to explore this area of high importance.

\section{CONCLUSION}

The use of illegal liquors "tharra" is on the rise in Pakistan, mainly due to the difference in price between homemade "tharra" and registered standard alcohol brands and due to the ban on use and purchase of alcohol products for Muslims in Pakistan. The tharra is very toxic-poison. However, it seems impossible for the Government to subsidize its prices or lift ban on use and purchase of standard alcohol products due to social and religious reasons. Nevertheless, the Government needs to reinforce the laws governing sale of methylated spirits for industrial and commercial uses.

\section{ACKNOWLEDGEMENT}

The authors would like to thank US-Pakistan Centers for Advanced Studies in Water, Mehran University of Engineering \& Technology, Jamshoro, Pakistan, for providing full support throughout this project.

\section{REFERENCES}

[1] Lachenmeier, D.W., and Rehm, J., "Is There a Relationship between Alcohol Quality and Health"? Alcohol and Alcoholism, 2012.
World Health Organization, "Pakistan Alcohol Consumption Level and Pattern”, 2014. http:// www.who.int/substance_abuse/publications/ global_alcohol_report/profiles/pak.pdf (Accessed on 25 $5^{\text {th }}$ October, 2016)

[3] Kloskowski, G.,and Mikulski, D., "The Effect of Raw Material Contamination with Mycotoxins on the Composition of Alcoholic Fermentation Volatile ByProducts in Raw Spirits”, BioSource Technology, No 101, pp. 9723-9727, 2010.

[4] Savchuk, S.A.,Nuzhnyi, V.P.,and Kolesov, G.M., "Factors Affecting the Accuracy of the Determination of Diethyl Phthalate in Vodka, Ethanol, and Samples of Illegal Alcoholic Products”, Journal of Analytical Chemistry, Volume 12, No. 61, pp. 1198-1203, 2006.

[5] Pino, J.A., "Characterization of Rum Using Solid-Phase Microextraction with Gas Chromatography - Mass Spectrometry”, Food Chemistry, Volume 19, No. 104, pp. 421-428, 2007.

[6] Pino, J.,Martí, M.,Mestres, M., Perez, J., Busto, O.,and Guasch, J., "Headspace Solid-Phase Microextraction of Higher Fatty Acid Ethyl Esters in White Rum Aroma”, Journal of Chromatography-A, Volume 954, pp. 51-57, 2002.

[7] Nonato, E.A.,Carazza, F., Silva, F.C.,Carvalho, C.R.,Cardeal, Z., and de, L., "A Headspace Solid-Phase Microextraction Method for the Determination of Some Secondary Compounds of Brazilian Sugar Cane Spirits by Gas Chromatography”, Journal of Agricultural and Food Chemistry, Volume 49, No. 123, pp. 3533-3539, 2001.

[8] Wang, M.L., Wang, J.T.,and Choong, Y.M., “A Rapid and Accurate Method for Determination of Methanol in Alcoholic Beverage by Direct Injection Capillary Gas Chromatography”, Journal of Food Composition and Analysis, Volume 8, No. 17, pp. 187-196, 2004.

[9] Fan, W., andQian, M.C., "Identification of Aroma Compounds in Chinese 'YangheDaqu' Liquor by Normal Phase Chromatography Fractionation Followed by Gas Chromatography [Sol] Olfactometry”, Flavour and Fragrance Journal, No. 21, pp. 333-342, 2006.

[10] Benn, S.M., andPeppard, T.L., "Characterization of Tequila Flavor by Instrumental and Sensory Analysis”, Journal of Agricultural and Food Chemistry, No. 44, pp. 557-566, 1996.

[11] Da Porto, C.,Cordaro, F.,and Marcassa, N., "Effects of Carbohydrate and Noncarbohydrate Sweeteners on the Orange Spirit Volatile Compounds”, LWT-Food Science and Technology, No. 39, pp. 159-165, 2006. 
[12] García-Llobodanin, L.,Ferrando, M.,Guell, C.,and Lopez, F.,'Pear Distillates: Influence of the Raw Material Used on Final Quality", European Food Research and Technology, Volume 228, pp. 75-82, 2008.

Soufleros, E.H.,Mygdalia, A.S., and Natskoulis, P., "Characterization and Safety Evaluation of the Traditional Greek Fruit Distillate”Mouro” by Flavor Compounds and Mineral Analysis", Food Chemistry, Volume 1, No. 86, pp. 625-636, 2004.

[14] Spaho, N.,Durr, P.,Grba, S.,Velagic-Habul, E.,and Blesic, M., "Effects of Distillation Cut on the Distribution of Higher Alcohols and Esters in Brandy Produced from Three Plum Varieties”, Journal of the Institute of Brewing, No. 119, pp. 48-56: 2013.

[15] Senorans, F.J., Ruiz-Rodriguez, A., Ibanez, E.,Tabera, J.,and Reglero, G., "Optimization of Countercurrent Supercritical Fluid Extraction Conditions for Spirits Fractionation”, Journal of Supercritical Fluids, No. 21, pp. 41-49, 2001.

[16] Rodríguez, M.R.,and Suarez, V.B., "Determination of Volatile Compounds in Cider Spirits by Gas Chromatography with Direct Injection”, Journal of Chromatographic Science, No. 45, pp. 428-434, 2007.

[17] Picinelli, A., Suarez, B., Moreno, J., Rodríguez, R.,CasoGarcía, L.M., and Mangas, J.J., "Chemical Characterization of AustrianCider”, Journal of Agricultural and Food Chemistry, No. 48, pp. 3997-4002, 2000.

[18] Lachenmeier, D.W., Sarsh, B., and Rehm, J., "The Composition of Alcohol Products from Markets in Lithuania and Hungary, and Potential Health Consequences: APilot Study”, Alcohol and Alcoholism, Volume 1, No. 44, pp. 93-102, 2009.

[19] Tumwesigye, N.M., and Kasirye, R., "Gender and the Major Consequences of Alcohol Consumption in Uganda”, Alcohol, Gender and Drinking Problems, pp. 189, 2005.

[20] Obaid-ur-Rahman, M.U., Ahmed, T.A., Rahman, S., and Atiqur, R., "Effects of Socioeconomic Factors, Psychological Stress, Smoking, Alcohol and Caffeine on Preterm Delivery”, Pakistan Journal of Pharmaceutical Sciences, Volume 11, pp.35-39, 1998.

[21] Das, S.K., Balakrishnan, V., and Vasudevan, D.M., "Alcohol: Its Health and Social Impact in India”, The National Medical Journal of India, Volume 19, No. 2, pp. 94-9, 2005.

[22] Bondy, S.J., Rehm, J., Ashley, M.J., Walsh, G., Single, E., and Room, R., "Low-Risk Drinking Guidelines: The Scientific Evidence”, Canadian Journal of Public Health, Volume 90, No. 4, pp. 264-70, 1999.
Lachenmeier, D.W., Anh, P.T.H., Popova, S., and Rehm, J., "The Quality of Alcohol Products in Vietnam and its Implications for Public Health”, International Journal of Environmental Research in Public Health, Volume 6, No. 155, pp. 2090-2101, 2009.

[24] Butt, M., "Use of Illegal Toxic Alcohol is Killing Hundreds Every Year in Pakistan; Family Physicians Have to Play a More Proactive Role in Saving Precious Lives”, Middle East Journal of Business, Volume 10, No. 2, pp. 48-53, 2015.

[25] European Commission, Commission Regulation No. “2870/2000 Laying Down Community Reference Methods for the Analysis of Spirits Drinks”, Official Journal of European Communities, No. 333, pp. 20-46, 2000 .

[26] Basu, D., Ghosh, A., Hazari, N., and Parakh, P., "Use of Family CAGE-AID Questionnaire to Screen the Family Members for Diagnosis of Substance Dependence”, Indian Journal of Medical Research, Volume 1, No. 143, pp. 716-722, 2016.

[27] Rehm, J., Room, R., and Monteiro, M., "Alcohol as a Risk Factor for Global Burden of Disease”, European Addiction Research, Volume 9, No. 4, pp. 157-164, 2003.

[28] Rehm, J., Sulkowska, U., and Manczuk, M., "Alcohol Accounts for a High Proportion of Premature Mortality in Central and Eastern Europe”, International Journal of Epidemiology, Volume 36, No. 2, pp. 458-67, 2007.

[29] Kruse, J.A.,’'Methanol Poisoning”, Intensive Care Med, Volume 18, pp. 391-7, 1992.

[30] Paine, A.J., and Dayan, A.D., "Defining a Tolerable Concentration of Methanol in Alcoholic Drinks", Human \& Experimental Toxicology, Volume 20, No. 11, pp. 563-568, 2001.

[31] Haider, W.A., and Chaudhry, M.A., "Prevalence of Alcoholism in the Punjab, Pakistan", Biomedical, Volume 24, pp. 80-84, 2008.

[32] Chaudhury, S., Das, S.K., Mishra, B.S., Ukil, B., Bhardwaj, P., Bhardwaj, R., and Dinker, N.L., "Physiological Assessment of Male Alcoholism”, Indian Journal of Psychiatry, Volume 44, No. 2, pp. 144, 2002.

[33] Kilonzo, G.P., "Pilot Study on Patterns of Consumption of Nonindustrial Alcohol Beverages in Selected Sites, Dar es Salaam, Tanzania”, Moonshine Markets, Issues in Unrecorded Alcohol Beverage Production and Consumption, Haworth, A., and Simpson, R., (Editors), Brunner-Routledge, Volume 1, pp. 67-86, New York, 2004.

[34] Dewan, G., and Chowdhury, F.R., "Alcohol Use and Alcohol Use Disorders in Bangladesh”, Asia Pacific Journal of Medical Toxicology, Volume 20, No. 4, pp. 83-90, 2015. 